\title{
Hindsight rather than foresight: reality versus the EU draft guideline on pharmaceuticals in the environment
}

\author{
Evelyn O’Brien and Daniel R. Dietrich
}

Environmental Toxicology, University of Konstanz, Konstanz, D-78457, Germany

\begin{abstract}
The strategy of passing much of European Union (EU) waste water through a sewage treatment plant (STP) before discharging it into rivers or lakes has done much to improve the quality of our inland waterways. But we still face a very worrying situation. Environmental problems have surfaced in conjunction with the STPs and their effluent recipients, and attention has turned to human pharmaceuticals and endocrine active substances, in particular, as another source of potential pollutants. Trying to assess the detrimental effects of these chemicals on the aquatic environment represents an extreme cost in terms of animals, time and finance. Instead, it would be better to go back to basics and to prevent entry of these substances into our aquatic environment.
\end{abstract}

In the 1960s and 1970s, alarm bells began to ring worldwide, and in several European states in particular, that Europe's inland waterways were suffering under the burden of contaminants such as phosphates from industrial and domestic waste. The overt eutrophication led to antipollution initiatives (e.g. the urban wastewater treatment directive for integrated pollution and prevention control; see Table 1) in several countries, culminating in a reduction in point-source discharges of organic matter, phosphates and, eventually, nitrates.

At present, about $80 \%$ of EU waste water passes through a sewage treatment plant (STP) before it is discharged into rivers or lakes (see European Chemicals Bureau website, Table 1). This strategy has been relatively successful in improving the quality of water in these waterways [1]. Despite this achievement, there is little cause for sitting back and enjoying the laurels of the technological success. In reality the reverse is true: we are currently looking at a very worrying situation.

Not all STPs in Europe operate to the same technological standards in terms of solids removal, flocculation and sedimentation, phosphate precipitation and denitrification. Furthermore, the number of inhabitants per STP, and thus the efficacy of STPs in removing xenobiotics, is highly variable. In actuality, the average number of inhabitants per STP has been steadily increasing owing to a growing

Corresponding authors: Evelyn O’Brien (evelyn.obrien@uni-konstanz.de) or Daniel R. Dietrich (daniel.dietrich@uni-konstanz.de). urban population; moreover, this increase in STP burden has occurred alongside a trend towards decreasing investment in the technical refurbishment and upgrading of STPs (M. Boller, pers. commun.; see also Table 1). Such factors lead to a decrease in STP efficacy and thus to a higher impact of effluents on the receiving surface waters.

Last but not least, surface waters that receive effluent from STPs rarely receive effluent that has the originally proposed effluent-to-surface water ratio of 1:10, which is still maintained as the default ratio for risk assessment purposes [2]. Indeed, dilution ratios range more typically between 1:1 and 1:5, especially for most of the receiving surface waters throughout Europe (M. Boller, pers. commun.; see also Table 1).

\section{Endocrine active substances and pharmaceuticals}

Considering the current high-throughput of STPs (i.e. a low residence time of effluent in the STP), the inadequate retention and reduction of some compounds during treatment, as well as the above-mentioned dilution factors, it is hardly surprising that additional environmental problems have surfaced more recently in relation to STPs and their effluent recipients. Indeed, the focus of attention has turned to another group of potential water pollutants, namely, human pharmaceuticals and endocrine active substances in particular, some of which (e.g. $17 \alpha$-ethinylestradiol and selective serotonin re-uptake inhibitors) belong to both categories [3,4].

These chemicals have been suggested to be responsible for several effects, such as reduced reproductive success in aquatic organisms, and thus have become a subject of great concern and intense and costly research over the past decade. Indeed, feminizing effects have been reported in wild fish living in rivers that receive effluent containing hormones or hormone-mimicking compounds ('endocrine disruptors') [5-12].

Surprisingly, however, most researchers supported by national and European Commission funding have focused almost solely on hormone mimics and the potential effects of these substances on the aquatic environment. Conversely, studies aimed at determining the source of the estrogenic activity present have concluded that natural and not artificial estrogens (hormone mimics) contribute more than $95 \%$ of the estrogenic activity detectable in the effluent [13-17], which shows that the basic problem lies 
Table 1. URLs relevant to waste-water treatment and pollution from pharmaceuticals

\begin{tabular}{|c|c|c|}
\hline Information & Website & URL \\
\hline \multicolumn{3}{|l|}{ Waste-water treatment } \\
\hline Directives & Water Intelligence Online & http://www.iwaponline.com/wio/2002/03/wio200203021.htm \\
\hline Effect of population growth on STPs & $\begin{array}{l}\text { The Alfa Laval International } \\
\text { Customer Magazine }\end{array}$ & http://here.alfalaval.com/zino.aspx?pagelD $=3 \&$ articlelD $=509$ \\
\hline Population growth in Germany & Unwelt Bundes Amt & $\begin{array}{l}\text { http://www.umweltbundesamt.de/uba-info-daten-e/daten- } \\
\text { e/population-growth.htm }\end{array}$ \\
\hline Dilution ratios for receiving surface waters & $\begin{array}{l}\text { GREAT-ER (Geography- } \\
\text { referenced Regional } \\
\text { Assessment Tool for European } \\
\text { rivers) }\end{array}$ & http://www.great-er.org/files/webb_musk.pdf \\
\hline \multicolumn{3}{|l|}{ Aquatic pollution from pharmaceuticals } \\
\hline Effects of EDCs and environmental hormones & $\begin{array}{l}\text { Community Programme of } \\
\text { Research on Endocrine } \\
\text { Disrupters and Environmental } \\
\text { Hormones (COMPREHEND) }\end{array}$ & $\begin{array}{l}\text { http://www.europa.eu.int/comm/research/endocrine/pdf/env4- } \\
\text { ct98-0798.pdf }\end{array}$ \\
\hline Effects and analysis of EDCs & $\begin{array}{l}\text { EDEN (Endocrine Disruption } \\
\text { Research) }\end{array}$ & http://www.edenresearch.info/aims.html \\
\hline $\begin{array}{l}\text { Pharmaceutically active substances in the } \\
\text { environment }\end{array}$ & ISWA, Abt. Hydrochemie & http://www.uni-stuttgart.de/siwa/ch/forschung/pharmaka.html \\
\hline Safety and evaluation of medicines & $\begin{array}{l}\text { EMEA (European Agency for } \\
\text { the Evaluation of Medical } \\
\text { Products) }\end{array}$ & http://www.emea.eu.int \\
\hline \multicolumn{3}{|l|}{$\begin{array}{l}\text { Solutions for reducing the environmental impact } \\
\text { of pharmaceuticals }\end{array}$} \\
\hline Environmental effects of veterinary medicines & $\begin{array}{l}\text { ERAVMIS (Environmental Risk } \\
\text { Assessment of Veterinary } \\
\text { Medicines in Slurry) }\end{array}$ & http://www.cranfield.ac.uk/ecochemistry/eravmis \\
\hline Removal of pharmaceuticals from sewage & $\begin{array}{l}\text { RemPharmaWater; } \\
\text { EU-Project Poseidon }\end{array}$ & $\begin{array}{l}\text { http://www.cdcs.unina.it/-rmarotta } \\
\text { http://www.eu-poseidon.com }\end{array}$ \\
\hline Assessment of urine source separation & Novaquatis & http://www.novaquatis.eawag.ch \\
\hline
\end{tabular}

${ }^{a}$ Abbreviations: EDC, endocrine-disrupting compound; EU, European Union; STP, sewage treatment plant.

with the STP and not with the hormone mimics. Correspondingly, most research efforts invested in the elucidation of 'endocrine disruption' have been spent on an extremely small - albeit not negligible - proportion of the total endocrine activity in STP effluents. By contrast, the overwhelming contributions of natural hormones, originating from human excreta as well as industrialized farming, have been largely ignored.

Furthermore, many of the effects observed in field studies carried out in proximity to STP effluent discharge sites have been ascribed to hormone mimics by mere association - that is, by virtue of single-organism and single-compound chronic tests and the presence of these compounds in very low concentrations in the effluent rather than by concrete causality. Although risk assessment based on single compounds is a matter of longstanding practice, the question of its relevance and rationality with respect to both the aquatic environment as a whole and its cost in terms of manpower and animals, is surely worth considering. Indeed, STP effluents are by no means constant with regard to their chemical composition, which varies markedly depending on the type and proportion of raw sewage dominating the inflow.

The EDEN project (Table 1), which is currently being funded by the EU, has the ambitious aim of assessing the potential detrimental effects of mixtures of endocrinedisrupting compounds (EDCs) and of developing criteria for relevant low-dose studies. Although this is a laudable goal, its significance for the environment must be questioned, because the results obtained will be reliable only for the particular combinations of chemicals tested. Such limited applicability of the results has direct relevance for STP effluents, which are indeed made up of mixtures of EDCs and other pharmaceuticals and organics (Ref. [13]; and see Comprehend website, Table 1). When mixtures are tested, conclusions can be drawn only for a particular sample or moment in time and not for any other potential cocktails. Thus, mixture studies can provide data that, at best, explain some observed effects in hindsight but allow no foresight; in other words, the data have no predictive and therefore no practical capability.

Because the constituents of STP effluents are subject to continual variation, it could be argued that the results yielded are only of theoretical value. Consequently, neither on-site field studies [12] nor artificial studies of mixtures in laboratories can establish plausible cause-and-effect relationships that are amenable to risk assessment and risk reduction purposes beyond describing, for example, that effluents can have feminizing effects in fish. Despite this - and surprising as it might seem - more efforts are currently directed towards establishing risk assessments of individual compounds that possibly emanate from STPs, rather than towards improving the technical capabilities of the STPs. If the STPs could reduce not just a maximum of $5 \%$ of the endocrine activity but nearly $100 \%$ instead, the problem of the effluent mixture would be solved.

With regard to this, the results of the recently completed Comprehend project (Ref. [13] and Table 1) clearly indicate that most endocrine activity is removed during secondary treatment (flocculation and sedimentation) 
and that one of the chief factors that influences the 'estrogenicity' of the final effluent is the residence time of the waste water in treatment. This finding, however, does not apply to pharmaceutically active compounds, for which additional technological improvements are necessary. Longer residence times combined with additional improvements to the STP process, for example, the addition of active charcoal (see below), have the potential to reduce to nearly zero the endocrine-disrupting capacity and the presence of pharmaceuticals in the STP effluent.

Without a doubt, issues remain to be resolved concerning the costs at which these technological improvements can be achieved and whether or not the resulting residues (wasted active charcoal) can be reactivated, incinerated or deposited in such a manner that no subsequent environmental hazard is created. Current results from projects heading in this direction (see the ISWA, Abt. Hydrochemie website, Table 1) are promising and seem to reinforce the idea that this might be indeed a viable solution to this pending problem.

\section{Pharmaceuticals and environmental risk assessment}

In view of the fact that estrogenic compounds are found in STP effluents, it should not be surprising that an evergrowing list of other pharmaceuticals used in human medicine and their metabolites have been reported to be present in surface waters including salbutamol, paracetamol, acetylsalicylic acid, chloramphenicol and diazepam, to name but a few $[18,19]$. This plethora of reports presumably reflects an increase in urbanization, a decrease in quality of sewage treatment and an improvement in analytical methods with lower detection limits.

On the basis of increasing pressure from environmental protection groups and growing public awareness and concerns about the possible impact of human pharmaceuticals on the environment, the EU has designed a draft document outlining a step-wise, phased procedure for the environmental risk assessment (ERA) of such substances. This draft has been designed to encompass ERAs for both new and renewed medicinal products, as well as for those subject to type II variations, that is, the incorporation of new indications or an increase in use of the product. On the basis of comments and input from experts, the draft document has been revised several times since its inception by the safety working party (June 1999 to November 2000); it was re-released for consultation in July 2003, with a deadline for comments of January 2004, and is to be finalized and written into European law.

The intention of this guideline is the protection of the environment against potential hazards posed by human pharmaceuticals. In this regard, it is primarily the aquatic environment that is intended, because such substances and/or their metabolites are excreted and reach STPs, where they might not be sufficiently broken down or retained before discharge of the treated waste water [2]. The draft document requires that "an application for the marketing authorisation for a medicinal product for human use shall be accompanied by an environmental risk assessment" and that "the applicant indicate any potential risks exhibited by the medicinal product for the environment", and relates "to those risks to the environment arising from use, storage and disposal of the medicinal product".

The proposal describes a step-wise two-tiered analysis of potential environmental effects. The initial assessment (phase I) should consist of an estimation of the exposure of the environment to the pharmaceutical in question, taking into account the estimated yearly production and market penetration, as well as the predicted degradation of the pharmaceutical in the STP and in the environment. Phase II should assess the physicochemical, pharmacological and toxicological properties. This EU draft document proposes phase II testing of all substances with a predicted environmental concentration (PEC) of $0.01 \mu \mathrm{g} / \mathrm{l}$ or higher and/or with a specific mode of action (MOA) such as direct or indirect interaction with a receptor (e.g. the estrogen receptor).

Because all pharmaceuticals, by definition, have been designed to have a specific MOA, this automatically obligates the testing of all human pharmaceuticals. Although pharmaceuticals with a specific MOA will be discussed on a case-by-case basis by the European Agency for the Evaluation of Medicinal Products (EMEA; see Table 1), these discussions will most probably result in the demand for animal- and cost-intensive, prolonged, acute, subchronic or chronic studies. Considering the number of compounds involved - there are about 900 different active ingredients registered for use in human medicine in Germany [20] and an even higher number in the United Kingdom [18] - the demand for long-term studies for ERA will be extremely intensive in terms of cost, time and animals. Indeed, animal- and cost-reduction strategies are already being discussed in industry to curtail fish toxicity studies with little or no value for ERA [21].

Perhaps an even greater inconsistency is the fact that PECs are to be calculated on a national basis, despite the fact that high concentrations of pharmaceuticals present in effluent are primarily restricted to the local environs of the STP (i.e. a point source) and that the concentration of any given contaminant is inversely proportional to its distance from the point of entry [22,23]. This latter aspect is considered in the draft document: the local PEC is based on the dilution factor attributed to the water body as a whole and thus does not consider the possibility of localized peak concentrations.

Another related aspect is the occurrence of seasonal variations in both the quantity and the class of substances being prescribed. For example, the higher prescription rate of antibiotics during winter months could result in higher quantities being discharged. This higher winter discharge can be partially offset by higher precipitation rates in some countries, such as the United Kingdom, and therefore greater dilution factors [18]. In more alpine countries and Scandinavia, however, winter months generally correspond to lower water levels and flow, and thus to lower effluent dilution factors. By contrast, the use of anti-inflammatory, antihistamine and analgesic preparations tends to be higher during the summer months, and thus concentrations might be higher, especially when environmental factors such as lower precipitation (e.g. drought periods in Spain and Portugal) are taken into account. 


\section{Predictions and facts}

Most of the testing systems stipulated by the current draft document are acute toxicity tests. In addition, long-term 'no observable effect concentrations' are to be used to generate 'predicted no effect concentrations' and assessment factors. The use of acute:chronic ratios as a means of identifying pharmaceuticals that pose a risk to the aquatic environment, as suggested by Webb [24], might present an avenue for the further definition of risk. Unfortunately, the dearth of chronic toxicity data precludes the generation of such ratios. This problem is shared with the current EU draft document. It seems as though no short cuts can be taken because only chronic toxicity datasets will allow the generation of a reliable ERA for just a single substance. Even if this is carried out, however, the potential for additive, synergistic or, on the positive side, annulatory effects of mixtures of substances in the cocktails released from STPs will still remain a black hole in terms of knowledge.

A further consideration is the observation that several substances, although predicted to be present in the effluent of STPs at extremely high percentages of the initial influent, have not been found in the aquatic environment $[18,19,25]$. This observation is presumably a result of difficulties in current analysis methods, but the possibility that unpredictable interactions and reactions take place in the STPs themselves, resulting in a far higher degree of degradation than predicted, should not be ignored. By contrast, conjugated metabolites can be metabolized by bacteria in the activated sludge to yield the parent compound, once again raising actual concentrations in the STP effluent.

All things considered, perhaps it would be better to go back to basics and to prevent the entry of pharmaceuticals into the aquatic environment instead of trying to assess their detrimental effects at an extreme cost in terms of animals, time and finance. In the 1980s, STPs were developed and improved with the aim of preventing the delivery of organic material, phosphates and nitrates into receiving waters. In reality, would the modernization and expansion of STPs to reduce the amount of human pharmaceuticals that actually enter the aquatic environment, rather than the testing of individual substances and specific mixtures that might or might not appear in the environment, not represent a more reasonable and economical course of action?

Indeed, a recent study carried out by Kirk et al. [26] in five different STPs has demonstrated the removal of estrogenic activity at levels of $70-100 \%$, depending on the treatment process employed. Furthermore, recent results from Comprehend (Ref. [13] and Table 1) strongly suggest that almost complete elimination of estrogenic activity in sewage effluents can be achieved if the residence time in STPs is increased. An increased residence time alone might not, however, be sufficient for complete removal of other pharmacologically active compounds for which additional technological improvements might be necessary to enhance removal during the sewage treatment process. In addition, three European research projects (ERAVMIS, RemPharmaWater and Poseidon; see Table 1) have investigated the environmental impact of human and veterinary pharmaceuticals and have attempted to design solutions to this complex problem, for example, the introduction of active charcoal or ozonation in sewage treatment.

A recent report carried out by the partners of the Poseidon working group has described the successful implementation of a pilot scheme for removing antibiotics from STP effluent in an STP in Braunschweig in Germany. This study has shown that ozone-based oxidation can completely eliminate antibiotics from treated waste water. The potential of ozonation for the elimination of other pharmaceuticals remains to be determined, but its use in combination with membrane filtration has been suggested by Heberer [27] and Jeckel [28].

A further step is currently being investigated at the Swiss Federal Institute for Environmental Science and Technology. The Novaquatis project (Table 1) is examining the potential of urine source separation with a view to better waste-water management. This research has its foundations in the fact that, although urine constitutes less than $1 \%$ of total waste-water volume, most of the nutrients and micropollutants (including pharmaceuticals) found in waste water originate from urine; thus, the use of 'NoMix toilets', which separate urine from the general sewage system for separate treatment, could help to alleviate the inadequacies of the STPs.

\section{The way forward?}

Perhaps a little retrospection and learning from past success in the reduction of eutrophication, rather than the analysis of potential detrimental effects, could yield more efficient and cost-effective solutions to the problem of human pharmaceuticals in the aquatic environment. In conclusion, the available data strongly suggest that it might be more worthwhile to invest time and finances in upgrading and scaling-up STPs rather than concentrating on the micromanagement of single compounds, which has little effective impact on the protection of our aquatic environment. This will not assuage industry from preparing the necessary risk documentation on the products to be marketed; however, a more focused approach will be of benefit to society as a whole, especially in view of the major problems in conserving potable water that we must face in the near future.

\section{References}

1 EEA (1999) Environment in the European Union at the Turn of the Century, European Environment Agency, Copenhagen

2 EMEA (2003) Draft Note for Guidance on Environmental Risk Assessment of Medicinal Products for Human Use (CPMP/SWP/ 4447/00), pp. 1-22, European Agency for the Evaluation of Medical Products

3 Brooks, B.W. et al. (2003) Aquatic ecotoxicology of fluoxetine. Toxicol. Lett. 142, 169-183

4 Lange, R. et al. (2001) Effects of the synthetic estrogen $17 \alpha$-ethinylestradiol on the life-cycle of the fathead minnow (Pimephales promelas). Environ. Toxicol. Chem. 20, 1216-1227

5 Ahel, M. et al. (1994) Behaviour of alkylphenol polyethoxylate surfactant in the aquatic environment. I. Occurrence and transformation in sewage treatment. Water Res. 28, 1131-1142

6 Jobling, S. et al. (1998) Widespread sexual disruption in wild fish. Environ. Sci. Technol. 32, 2498-2506

7 Korner, W. et al. (2000) Input/output balance of estrogenic active compounds in a major municipal sewage plant in Germany. Chemosphere 40, 1131-1142 
8 Tanghe, T. et al. (1999) Nonylphenol and estrogenic activity in aquatic environmental samples. J. Environ. Qual. 28, 702-709

9 Ternes, T. et al. (1999) Behaviour and occurrence of estrogens in municipal sewage treatment plants. I. Investigations in Germany, Canada and Brazil. Sci. Total Environ. 225, 81-90

10 Kuch, H. and Ballschmiter, K. (2000) Determination of endogenous and exogenous estrogens in effluent from sewage treatment plants at the ng/L-level. Fresenius J. Anal. Chem. 366, 392-395

11 van der Aerle, R. et al. (2001) Sexual disruption in a second species of wild cyprinid fish (the gudgeon, Gobio gobio) in UK fresh waters. Environ. Toxicol. Chem. 20, 2841-2847

12 Jobling, S. et al. (2002) Altered sexual maturation and gamete production in wild roach (Rutilus rutilus) living in rivers that receive treated sewage effluents. Biol. Reprod. 66, 272-281

13 Pickering, A. and Sumpter, J.P. (2003) Comprehending endocrine disrupters in aquatic environments. Environ. Sci. Technol. 37, $331 \mathrm{~A}-336 \mathrm{~A}$

14 Desbrow, C. et al. (1998) Identification of estrogenic chemicals in STW effluent. I. Chemical fractionation and in vitro biological screening. Environ. Sci. Technol. 32, 1549-1558

15 Lee, H.B. and Peart, T.E. (1998) Determination of $17 \beta$-estradiol and its metabolites in sewage effluent by solid-phase extraction and gas chromatography/mass spectrometry. J. AOAC Int. 81 (6), 1209-1216

16 Belfroid, A.C. et al. (1999) Analysis and occurrence of estrogenic hormones and their glucuronides in surface water and waste water in The Netherlands. Sci. Total Environ. 225, 101-108

17 Rodgers-Gray, T.P. et al. (2000) Long-term temporal changes in the estrogenic composition of treated sewage effluent and its biological effects on fish. Environ. Sci. Technol. 34, 1521-1528

18 Ayscough, N.J. et al. (2000) Review of Human Pharmaceuticals in the Environment: Technical Report, p. 390, Bristol Environmental Agency

19 Webb, S.F. (2001) A data-based perspective on the environmental risk assessment of human pharmaceuticals. II. Aquatic risk characterisation. In Pharmaceuticals in the Environment: Sources, Fate, Effects and Risks (Kümmerer, K., ed.), pp. 204-219, Springer-Verlag

20 Kümmerer, K. (2001) Introduction: pharmaceuticals in the environment. In Pharmaceuticals in the Environment: Sources, Fate, Effects and Risk (Kümmerer, K., ed.), pp. 1-8, Springer-Verlag

21 Hutchinson, T.H. et al. (2003) A strategy to reduce the numbers of fish used in acute ecotoxicity testing of pharmaceuticals. Environ. Toxicol. Chem. 22, 3031-3036

22 Balk, F. and Ford, R.A. (1999) Environmental risk assessment for the polycyclic musks, AHTN and HHCB in the EU. I. Fate and exposure assessment. Toxicol. Lett. 111, 81-94

23 Dietrich, D.R. and Hitzfeld, B.C. (2004) Bioaccumulation and ecotoxicology of synthetic musks in the aquatic environment. In The Handbook of Environmental Chemistry (Vol. 3) (Hutzinger, O., ed.), pp. 233-244, Springer-Verlag

24 Webb, S.F. (2001) A data-based perspective on the environmental risk assessment of human pharmaceuticals. I. Collation of available ecotoxicity data. In Pharmaceuticals in the Environment: Sources, Fate, Effects and Risks (Kümmerer, K., ed.), pp. 175-201, SpringerVerlag

25 Jones, O.A.H. et al. (2002) Aquatic environmental assessment of the top 25 English prescription pharmaceuticals. Water Res. 36, 5013-5022

26 Kirk, L.A. et al. (2002) Changes in estrogenic and androgenic activities at different stages of treatment in wastewater treatment works. Environ. Toxicol. Chem. 21, 972-979

27 Heberer, T. (2002) Occurrence, fate and removal of pharmaceutical residues in the aquatic environment: a review of recent research data. Toxicol. Lett. 131, 5-17

28 Jeckel, M. (2000) Full-scale applications. In Ozonation of Water and Waste Water (Gottschalk, C. et al., eds), pp. 21-36, Wiley-VCH Verlag 